Proc. Indian Acad. Sci. (Earth Planet. Sci.), Vol. 101, No. 4, December 1992, pp. 369-385.

C) Printed in India.

\title{
Identification of potential areas for the occurrence of strong earthquakes in Himalayan arc region
}

\author{
S C BHATIA ${ }^{1}$, T R K CHETTY ${ }^{1}$, M B FILIMONOV ${ }^{2}$, \\ A I GORSHKOV ${ }^{2}$, E Ya RANTSMAN ${ }^{3}, \mathrm{M} \mathrm{N} \mathrm{RAO}^{1}$ \\ ${ }^{1}$ National Geophysical Research Institute, Hyderabad, India \\ ${ }^{2}$ International Institute of Theory of Earthquake Prediction and Mathematical Geophysics, \\ Moscow, Russia \\ ${ }^{3}$ Institute of Geography, Moscow, Russia.
}

MS received 20 July 1992

\begin{abstract}
Morphost ructural zoning (MSZ) scheme of the Himalayan arc region as obtained from a joint study of topographic, geological and tectonic maps as well as satellite imagery is analysed. Three types of morphostructures have been determined: territorial units (blocks of different ranks), linear zones limiting these blocks (lineaments) and intersections of the lineaments (knots). Comparison of MSZ scheme with the known seismicity indicates epicenters of strong earthquakes $(M \geqslant 6.5)$ clustered around some of these knots. Pattern recognition method is used to determine seismically potential areas for the occurrence of strong earthquakes of magnitude $\geqslant M_{0}$. We have carried out two such studies for the Himalayan arc region, one for $M_{0}=6.5$ and the other for $M_{0}=7.0$. Out of a total number of $97 \mathrm{knots}, 48 \mathrm{knots}$ are found to be seismically potential for the occurrence of earthquake of $M \geqslant 6.5$. The results of the study for $M_{0}=6.5$ were presented in the symposium on "Earthquake Prediction" held in Strasbourg, France, March 1991 (Gorshkov et al 1991). The epicenter of Uttarkashi earthquake of magnitude, $M_{b}=6.6$ that occurred in the late hours of 19th October 1991 (UTC) lies in the vicinity of one such knot. The second study carried out subsequently shows that only $36 \mathrm{knots}$ are potential for the occurrence of earthquakes of $M \geqslant 7.0$, which include the knot associated with the Uttarkashi earthquake.
\end{abstract}

Keywords. Himalaya; morphostructural zoning; lineament; knot; pattern recognition; earthquake potential.

\section{Introduction}

The Himalayan arc region, the highest mountain chain on the earth stretching for about $2400 \mathrm{~km}$ between Kashmir in northwest India and Indo-Burma border in the east, is a well-known region of high seismic potential. In the light of plate tectonics theory, recent morphostructures of the Himalaya have been formed as a result of continent-continent collision between India and Eurasia. Interaction of these plates which started since Upper Cretaceous is still going on at the present time and is causing a high level of seismicity in the area.

Different sectors of the Himalayan region, however, have not experienced and may not experience the same level of seismicity in terms of frequency and magnitude. It is therefore necessary to distinguish the small territories of high seismic potential from those of less seismic potential within the large Himalayan arc region. Different approaches can be used for this purpose. One such approach is to determine zones of high seismic potential based on the analysis of geotectonic and morphostructural information and subjecting the same to an appropriate pattern recognition algorithm. 
In this approach the objects of recognition are the intersection points of two or more lineaments called knots. The numerical parameters extracted from the morphostructural features around these knots describe the object-vector. Appropriate recognition rules are derived using learning material and they are applied to the set of unclassified objects to classify them into the seismically potential or non-potential class. This method was successfully tested in many seismic regions of the world: Pamirs, Tian-Shan, Caucasus, Anatolia, Balkans, Italy, Alps, Pyrenees, California, Andes (Gelfand et al 1972; Rantsman 1979; Filimonov et al 1989).

The first attempt to apply pattern recognition method for the determination of earthquake prone areas in the Himalayas was made by Varunoday et al 1979, on the basis of geological data. In our study we investigate this problem using pattern recognition algorithm on morphostructural data.

Morphostructural knots form the objects for recognition in our study because of the fact that all the known epicenters of strong earthquakes are found located in the near vicinities of such knots. It is further hypothesized that the epicenters of future earthquakes would also be associated with knots. The validity of this hypothesis is discussed by Rantsman (1979) and the statistical testing by Gvishiani and Soloviev (1981).

\section{Morphostructural zoning of mountain territories}

Morphostructural knots, denoted as the objects of recognition of possible strong earthquake areas, are determined from a scheme of morphostructural zoning (MSZ). MSZ is based on the idea about block structure of the earth's crust. MSZ means the division of a territory into a system of hierarchically-ordered areas characterized by a definite degree of uniformity of the morphostructure.

Morphostructural analysis is based on the concept that tectonic movements have brought about changes in the earth's surface. This forms a part of earth sciences that deals with the relations between landforms and recent tectonic movements. It is a part of structural geomorphology, the purpose of which is to analyse all relations between geological structures and geomorphology. Determination of earthquake prone areas using recent relief data is based on the concept that the large elements of relief in the mountain territories represent in some way or other the tectonic movements at the depth comparable with those of shallow earthquakes.

Three types of morphostructures are identified in MSZ: territorial units (blocks); linear zones separating blocks (morphostructural lineaments); and the intersections of various lineaments (morphostructural knots). Blocks, lineaments and knots - in that order, are characterized by an increasing tectonic activity.

MSZ is hierarchically ordered and blocks are assigned with ranks. Mountain countries - considered as blocks of first rank - are divided into blocks of second rank called as megablocks. Megablocks are further subdivided into blocks of third rank called blocks. The rank of lineaments is also decided as first, second and third depending on their relation to mountain countries, megablocks and blocks respectively.

Morphostructural lineaments are zones of varying width upto a few tens of kilometers depending on the rank and their position against large relief elements. Longitudinal lineaments are generally parallel to the predominant strike of large elements of relief. They occur along the boundaries of these elements, separating the relatively 
elevated areas from those of lower elevation. Longitudinal lineaments are also characterized by contrasting types of relief and include the zones of large faults. Transverse lineaments are oriented across or at an angle to the predominant strike of large elements of relief. Their manifestations on the surface are normally discontinuous.

The knots include areas greater than the width of lineament zones that form the knot. The actual boundaries of the knots must be defined by field geomorphological investigations. In the absence of field investigations the boundary is considered as a circular area of a given radius around the knots. The centers of such circles are the points of intersections of lineaments. Radius of these circles is determined on the basis of the magnitude of the earthquake under consideration.

\section{Morphostructural zoning of the Himalaya}

The MSZ-scheme of the Himalaya (figure 1) is constructed in accordance with the rules described above. The main inputs used for this study are topographic, geological and tectonic maps as well as satellite imagery.

Four main tectonic zones are usually recognized in the Himalaya (Ganser 1964). They generally correspond to different hypsometric levels within southern and northern flanks of the Himalaya.

According to MSZ principles, the Himalaya is considered as a continuous mountain country with a common type of orogenesis and uniform appearance in relief. From Ganser's (1974) point of view, the Himalaya is a part of Indian platform, and it may be considered as epiplatformal orogeny. Khain (1984) considers the Himalaya as a typical folded orogeny of Alpine type with geosynclinal stages of evolution and regards it as epigeosynclinal type. However, it is known that this mountain country is a result of a common tectonic regime. Therefore, we consider it in the present study as a continuous first-rank territorial unit.

In general, the relief of the Himalaya is characterized by the presence of a continuous central axis, the flanks of which are deeply dissected by transverse river valleys and complicated by longitudinal valleys, isolated frontal ridges, intermontane basins and plateaus. Orientation of ridge axis and footline of the Himalayan range gradually changes from E-W direction in its central part, to NW-SE in the western part, and to NE-SW in the eastern part. The range is sharply asymmetrical, and its southern flank is much steeper than the northern one (figures 1 and 2).

\subsection{First rank lineaments}

The Himalayan range is separated from adjoining areas by first-rank morphostructural lineaments. Longitudinal first-rark lineaments separate this mountain country from the vast Indo-Gangetic accumulative plains in the south and from the Tibetan highland in the north. Transverse first-rank lineaments separate the Himalaya from Burma Ranges in the east and the Hindukush mountain chains in the west. The different segments within the lineaments are further described with reference to the numbers given to the knots, from west to east (figure 3 ).

The longitudinal lineament $1-93$ at the northern boundary limited by knot 1 in the west and 93 in the east corresponds to a complex deep-seated fault known as Indus-Tsangpo Suture Zone. This zone, characterized by numerous outcrops of 


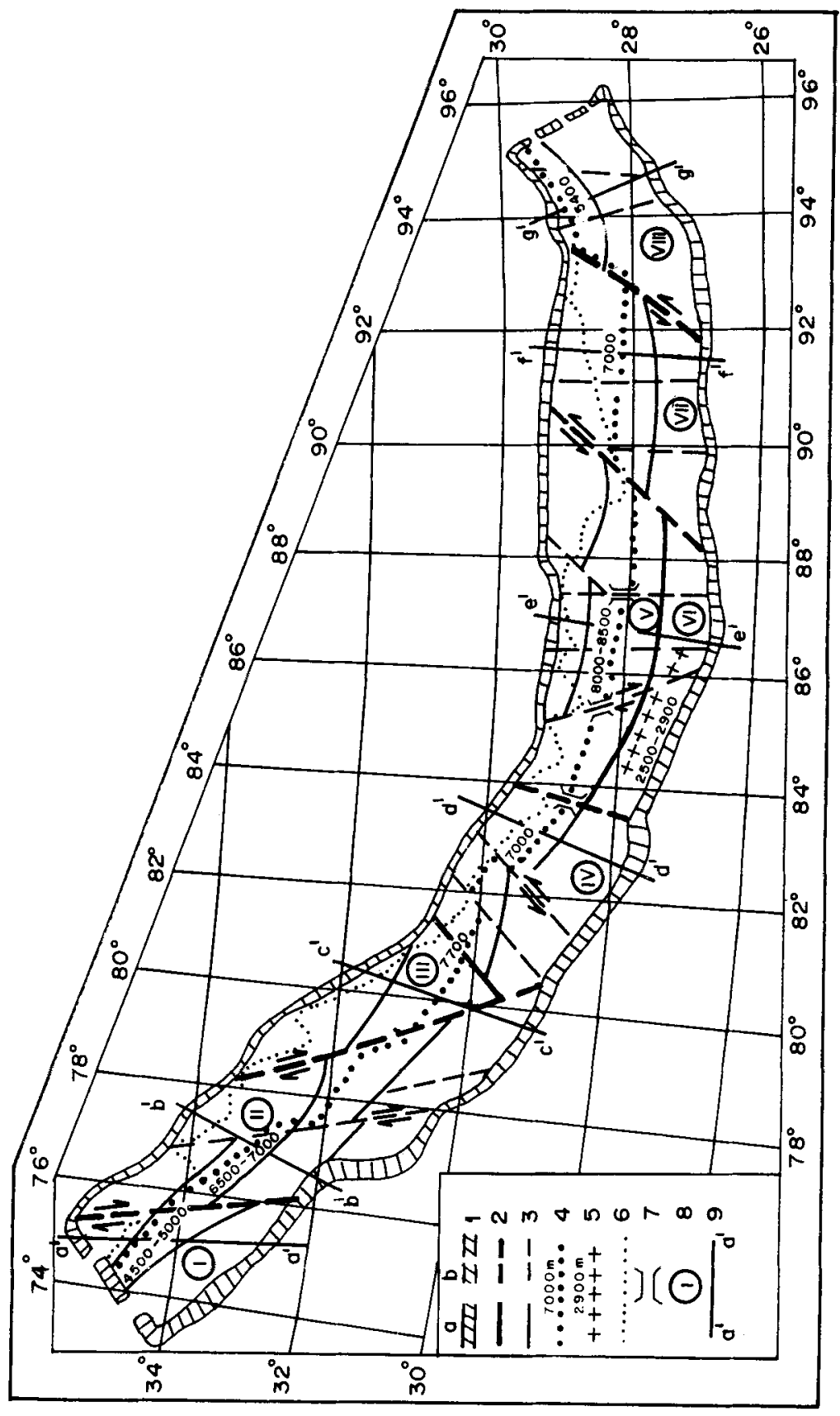

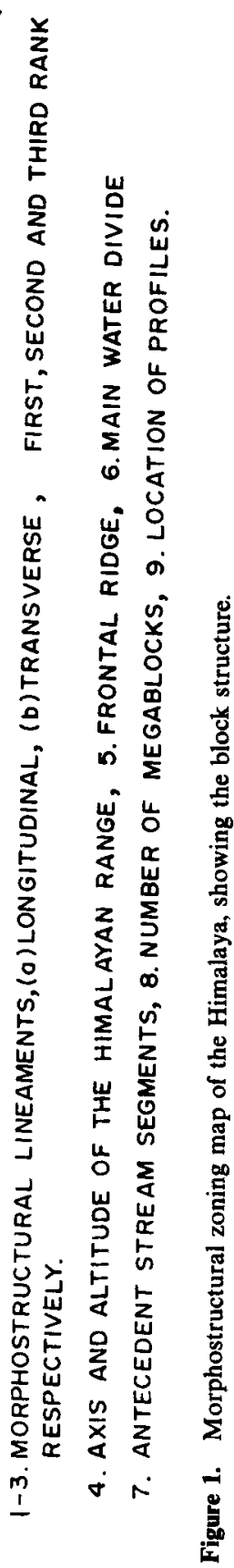



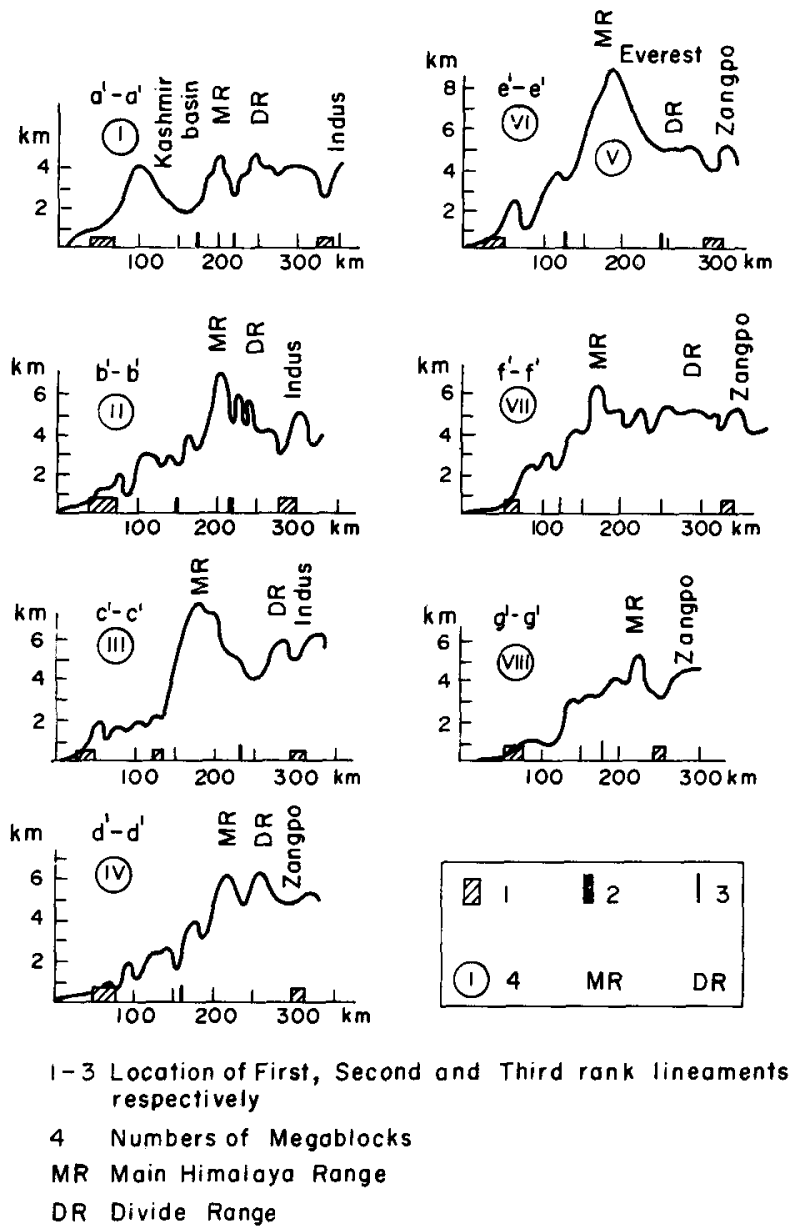

Figure 2. Topographic profiles in different megablocks.

ophiolites, is considered usually as a boundary between Indian and Eurasian plates (Valdia 1984; Windley 1988). The southern boundary lineament 5-96, is characterized by a very complicated inner structure. This zone of lineament includes two systems of subparallel faults namely Himalayan Frontal Thrust in the south and Main Boundary Thrust (MBT) in the north. The former lies between the foothills and the accumulative plains, while the latter separates foothills and mountain slope. The width of lineament zone varies from 10 to $35 \mathrm{~km}$. The segments of the lineament 5-18, 37-56 and 86-89 show maximum width. Along these segments, the mountain slope conjuncts with a broad strip of foothills suggesting that tectonic movements along these segments during orogenic period were not of considerable magnitude. The narrowing of strip of the foothills within the segments $18-37$ and 56-86 suggests an increase in magnitude of tectonic movements within them during the Quarternary time.

Western boundary lineament $1-5$, corresponds to a northeast oriented thrust (Valdia 1984). Eastern boundary lineament 93-96, is traced in accordance with a system of subparallel faults along the Mishmi Thrust. 


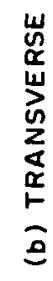

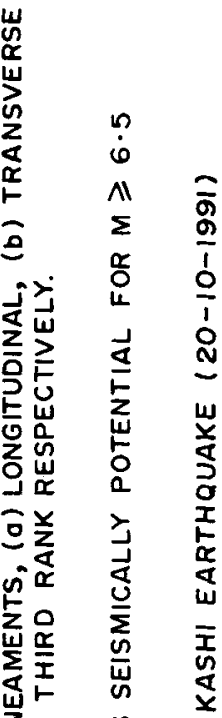

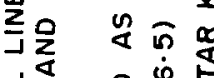

4 n $0 \dot{0} \mathbb{5}$

운

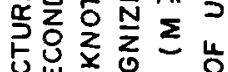

岁山员 n

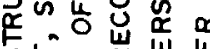

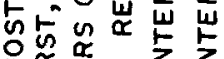

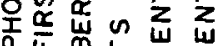

高范占

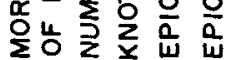

i $\nabla \dot{0} \dot{N}$

$\underline{1}$ 


\subsection{Second-rank lineaments}

Lineaments of second rank form boundaries of megablocks and are represented mainly by transverse lineaments. There is only one second rank longitudinal lineament mapped as the boundary between megablocks V and VI. Zones of transverse lineaments are mostly represented by rectilinear segments of river valleys extending in a common strike, transverse escarpments and along segments of known geological faults. Altitude and strike of the Himalayan range are sharply and considerably changed across the zones of transverse lineaments. Besides, axis and footline of the Himalayan range are also displaced by transverse lineaments.

\subsection{Megablocks}

The Himalayas are subdivided into 8 megablocks in accordance with the changes in altitude and strike of the main axis (figure 1). Their formalized characteristics are given in table 1 . These megablocks show different drainage-pattern and have varying shapes of topographic profiles (figure 2). Such different shapes of profiles may be related to the variations of stress-pattern along the Himalayan range. The details of each megablock are described below.

In megablock $\mathrm{I}$, the altitude of the Himalayan range is gradually lowered in an E-W direction from $5000 \mathrm{~m}$ to $4500 \mathrm{~m}$. However, the frontal ridge, the water divide and the axial range exhibit the same altitude. This implies a homogeneity in the deformation pattern within the block. The presence of a large intermontane Kashmir basin is distinct in this megablock from other ones.

In megablock II, the Himalayan range axis is oriented in a NW direction with an average altitude of $6500 \mathrm{~m}$. The axis attains its greatest altitude at the western and eastern margins of this megablock. The northern Himalayan flank inside the megablock is extremely short and steep and the width of the block increases to $170 \mathrm{~km}$ in the southern flank. The altitude of the Himalayan range suddenly increases to $7700-7800 \mathrm{~m}$ within the megablock III and its axis is displaced to the south by a considerable distance.

Table 1. Features of megablocks.

\begin{tabular}{lccc}
$\begin{array}{l}\text { N of } \\
\text { megablock }\end{array}$ & $\begin{array}{c}\text { Average altitude } \\
\text { of the Himalayan } \\
\text { range axis }(m)\end{array}$ & $\begin{array}{c}\text { Strike of the } \\
\text { Himalayan range } \\
\text { axis }\end{array}$ & $\begin{array}{c}\text { Regular changing } \\
\text { of the Himalayan } \\
\text { range of altitude }\end{array}$ \\
\hline I & $4500-5000$ & WNW-ESE & $\leftarrow$ \\
II & $6500-7000$ & NW-SE & $\rightarrow$ \\
III & 7700 & WNW-ESE & $\leftrightarrow$ \\
IV & 7000 & WNW-ESE & $\leftrightarrow$ \\
V & $8000-8500$ & W-E & $\rightarrow \leftarrow$ \\
VI & $\begin{array}{c}\text { does not include } \\
\text { Himalayan Range }\end{array}$ & W-E & $\rightarrow$ \\
VII & 7000 & NE-SW & $\leftarrow$ \\
VIII & 5400 & & $\rightarrow$
\end{tabular}

Note: $\rightarrow-$ trend of increase of the Himalayan Range altitude within megablock. 
To the east of Kali river, in megablock IV, the Himalayan range is lowered up to an elevation of $7000 \mathrm{~m}$ and maintains WNW orientation. Unlike others, this megablock consists of a large longitudinal valley developed between the Kali river and Kali-Gandak river. A large ridge is seen extending parallel to the Himalayan range south of this valley. The southern Himalayan flank in this megablock is 4 times larger in area than that of the northern flank.

Megablock $V$ occupies a central and highly elevated part of the Himalaya along with a wide plateau on its northern flank. The Himalayan axis in this block is shifted to south and the orientation becomes east-west. Its altitude attains a maximum of $8000-8800 \mathrm{~m}$ which is significantly the highest on the earth.

Megablock VI, located in the southern flank south of Mount Everest, is characterized by a combination of frontal ridge of $2900 \mathrm{~m}$ elevation and a well-developed longitudinal valley. Frontal ridge is separated from the Himalayan range by Son Kosi valley and a large intermontane depression is located, west of Kathmandu.

In megablock VII, the Himalayan axis is shifted to north and its altitude goes down to $7000 \mathrm{~m}$. The southern flank is relatively very narrow inside this megablock when compared to others. A vast plateau occurs in the northern flank.

In megablock VIII, the Himalayan axis is shifted further to north and is oriented in the NE direction. Its altitude sharply decreases to $5400 \mathrm{~m}$.

\subsection{Third-rank lineaments and blocks}

The third rank longitudinal lineaments divide the Himalaya into blocks according to their tectonic regionalization. They separate the Higher Himalaya (axial part of the Himalayan range) from the Lower Himalaya comprising lower part of the southern flank. The Tethys Himalaya represented by plateau-like surface in the northern flank are further separated by another set of third-rank lineaments. These zones of thirdrank lineaments include systems of large thrusts separating main tectonic units of the Himalaya.

Third-rank transverse lineaments are drawn connecting the points of change in the altitude and orientation of axes of Himalayan range. Many of them coincide with the known geological faults (Olta and Akiba 1973; Ganser 1983; Valdia 1976) as well as with some of the lineaments identified from satellite imagery (Mukhopadhyay 1984; Dasgupta et al 1987).

In summary, the morphostructural study presents a network of lineaments and a hierarchical system of territorial units in the region of Himalaya. Such a scheme of MSZ for the Himalaya may be considered as a model of recent block mosaic of the area. Relative displacement and interaction of different blocks of various ranks are perhaps the causative sources for the seismicity in the region.

\section{MSZ-scheme and seismicity of the Himalaya}

The Himalaya is characterized by a high level of seismicity. About 23 earthquakes with $M \geqslant 6.5$ based on the NOAA and Indian Meteorological Department Catalogues (table 2) are considered. The plot of these earthquakes with MSZ-scheme has shown that their epicenters are clustered around intersections of lineaments (knots) within a distance not greater than $50 \mathrm{~km}$ (figure 3 ). It is generally speculated that future 
Table 2. Shallow earthquakes of Himalaya region with $M \geqq 6.5$.

\begin{tabular}{|c|c|c|c|c|c|}
\hline \multirow[b]{2}{*}{ No. } & \multirow[b]{2}{*}{ Date } & \multicolumn{2}{|c|}{ Coordinates } & \multirow[b]{2}{*}{$M$} & \multirow{2}{*}{$\begin{array}{c}N \text { of neares } \\
\text { knot }\end{array}$} \\
\hline & & $\varphi(N)$ & $\lambda(E)$ & & \\
\hline 1 & 26.08 .1833 & $27 \cdot 50$ & 86.50 & $7 \cdot 5$ & 57 \\
\hline 2 & $18 \cdot 05.1852$ & $27 \cdot 00$ & 88.00 & $6 \cdot 5$ & 68 \\
\hline 3 & 30.05 .1885 & $34 \cdot 60$ & $74 \cdot 38$ & 7.0 & 4 \\
\hline 4 & 04.04 .1905 & $32 \cdot 30$ & $76 \cdot 25$ & 8.0 & 17 \\
\hline 5 & 28.02 .1906 & 32.00 & 77.00 & $7 \cdot 0$ & 18 \\
\hline 6 & 14.10 .1911 & 31.00 & $80 \cdot 50$ & 6.8 & 32 \\
\hline 7 & 03.02 .1915 & $29 \cdot 50$ & $91 \cdot 50$ & $7 \cdot 1$ & 75 \\
\hline 8 & 28.08 .1916 & 30.00 & $81 \cdot 00$ & $7 \cdot 5$ & 39 \\
\hline 9 & 27.05 .1936 & $28 \cdot 50$ & $83 \cdot 50$ & $7 \cdot 0$ & 49 \\
\hline 10 & 04.06 .1945 & $30 \cdot 30$ & $80 \cdot 00$ & $6 \cdot 5$ & 35 \\
\hline 11 & 22.06 .1945 & $32 \cdot 60$ & 75.90 & 6.5 & 9 \\
\hline 12 & 29.07 .1947 & $28 \cdot 80$ & $93 \cdot 70$ & $7 \cdot 7$ & 90 \\
\hline 13 & 16.08 .1950 & $27 \cdot 48$ & $92 \cdot 64$ & $6 \cdot 7$ & 85 \\
\hline 14 & 18.11 .1950 & $27 \cdot 73$ & 94.59 & $6 \cdot 7$ & 88 \\
\hline 15 & 12.03 .1951 & $28 \cdot 19$ & 94.49 & 6.5 & 89 \\
\hline 16 & 22.04 .1951 & $29 \cdot 21$ & $94 \cdot 30$ & $6 \cdot 5$ & 91 \\
\hline 17 & 23.02 .1954 & $27 \cdot 80$ & $91 \cdot 07$ & 6.5 & 77 \\
\hline 18 & 04.09 .1954 & $28 \cdot 30$ & 83.08 & 6.7 & 49 \\
\hline 19 & 29.07 .1960 & 26.90 & $90-30$ & 6.5 & 78 \\
\hline 20 & 06.03 .1966 & $31 \cdot 50$ & $80 \cdot 50$ & 6.5 & 32 \\
\hline 21 & 19.01.1975 & 32.45 & 78.43 & 6.8 & 28 \\
\hline 22 & 29.07 .1980 & 29.59 & 81.09 & 6.6 & 38 \\
\hline 23 & 20.08 .1988 & $26 \cdot 78$ & $86 \cdot 61$ & 6.5 & 56 \\
\hline
\end{tabular}

earthquakes with $M \geqslant 6.5$ are most likely to occur only within the knots identified from the MSZ-scheme.

\section{Pattern recognition approach}

Pattern recognition approach can be applied to delineate earthquake prone areas on a set of objects derived from the morphostructural zoning scheme of the region. The objects are described by using a set of parameters. Three broad types of parameters are generally used including geomorphological, geological and geophysical. These features are obtained from a circular area around the knot with a radius of $50 \mathrm{~km}$ considered comparable to the influence of an earthquake of magnitude 6.5 .

Pattern recognition algorithm "Cora-3" (Gelfand et al 1972) with learning stage is applied in our study. The algorithm on the basis of learning set can distinguish the seismically potential zones $(D)$ and non-potential zones $(N)$. However, during the learning stage a knot is considered to be of class $D_{0}$ if an earthquake with $M \geqslant 6.5$ had occurred during the past history within that knot. In case of absence of earthquakes of $M \geqslant 6.5$ within the knots, they are considered as class $N_{0}$. Characteristic features of these two classes are derived from the learning material and appropriate recognition rules are formulated. These recognition rules are then used to classify all 
the knots into either class $D$ (potential) or class $N$ (non-potential) indicating the zones of earthquake potential areas for $M \geqslant 6.5$.

We now introduce some definitions of symbols that are used in this algorithm.

- $W$ to be the general set of objects of recognition.

- $W_{0}=\left(D_{0}, N_{0}\right)$ to be the learning material $D_{0}, N_{0} \subseteq \cdot W, D_{0}$ corresponds to potential and $N_{0}$ corresponds to non-potential objects.

- $\Pi: W=D|-| N$ to be a classification of $W$ with algorithm $\Pi$ i.e. $\Pi: W=D|-| N$ to be a division of $W$ into two subsets $D$ and $N$ such that $D \cup N=W$ and $D \cap N=0$.

- $B_{p}=\{0,1\}^{p}$ to be the binary space of $p$ dimensions.

- $D: W \rightarrow B_{p}$ to be the binary description of objects, for each $w \in W \mathrm{~d}(w)=\omega=$ $\left(\omega_{1}, \ldots \omega_{i}, \ldots \omega_{p}\right)$.

The algorithm CORA-3 characterize the $D$-objects and $N$-objects by features, that is to say by some combination of values of the components of the binary vector representing the object in $B$ - space. This is a way to represent the joint occurrence of some physical properties and the features are defined in the form of a matrix:

$$
T=\left|\begin{array}{lll}
i_{1} & i_{2} & i_{3} \\
\alpha_{1} & \alpha_{2} & \alpha_{3}
\end{array}\right|
$$

where $i_{r}=1,2, \ldots, p ; \alpha_{r}=0$ or $1 ; r=1,2,3$.

An object $w \in W$ possesses the feature $T$ if $\omega_{i_{r}}=\alpha_{r}$ for its description $\mathrm{d}(w)$ in binary space $B_{p}$. Let $K_{D_{0}}(T)$ be the number of objects of class $D$ in $W_{0}$ and $K_{N_{0}}(T)$ number of objects of class $N$ containing the same feature. Let $K_{D}, \tilde{K}_{D}, K_{N}, \tilde{K}_{N}$ be some fixed free integers. The feature $T$ is considered to be a characteristic $D$-feature if

$$
K_{D_{0}}(T) \geqslant K_{D} \text { and } K_{N_{0}}(T) \leqslant \tilde{K}_{D}
$$

It is a characteristic $N$-feature if

$$
K_{N_{0}}(T) \geqslant K_{N} \text { and } K_{D_{0}}(T) \leqslant \tilde{K}_{N}
$$

For each $w \in W$ we define $\Delta(w)=N_{D}(w)-N_{N}(w)$ where $N_{x}(w)$ is number of features which appear in the object $w$. Let $\Delta_{t}$ be an additional free parameter. The classification

$$
\begin{gathered}
C\left(W_{0}, K_{D}, \tilde{K}_{D}, K_{N}, \tilde{K}_{N}, \Delta_{t}\right): W=D \cup N \text { is defined as } \\
D=\left\{w \in W: \Delta(w) \geqslant \Delta_{t}\right\} \\
N=\left\{w \in W: \Delta(w)<\Delta_{t}\right\}
\end{gathered}
$$

\section{Recognition of earthquake-prone areas in the Himalaya $(M \geqslant 6.5)$}

In total, 97 knots were obtained from the study of morphostructural zoning. The objective of the study is to classify them into two classes: potential $(D)$ non-potential $(N)$ for earthquakes of $M \geqslant 6.5$.

Among the knots 21 of them are found to be associated with the earthquake epicenters and they are regarded as learning set $D_{0}$ for $D$-class. The knots are: 4,9 , $17,18,28,32,35,38,39,49,56,57,68,75,77,78,85,88,89,90$ and 91.

Earthquakes with $6.0 \leqslant M \leqslant 6.4$ are known to occur in the knots namely $3,10,11$, 
Table 3. Parameters used for describing objects and thresholds for discretization $(M \geqslant 6.5)$.

\begin{tabular}{|c|c|c|c|}
\hline \multirow[b]{2}{*}{$\#$} & \multirow[b]{2}{*}{ Name of parameter } & \multicolumn{2}{|c|}{ Thresholds of coding } \\
\hline & & Lower & Upper \\
\hline 1 & $\begin{array}{l}\text { Minimum altitude in the vicinity of } \\
\text { knot, } H_{\min }, m\end{array}$ & $<300$ & $>2100$ \\
\hline 2 & $\begin{array}{l}\text { Difference between maximum and } \\
\text { minimum altitudes, } \Delta H\end{array}$ & $<2900$ & $>4400$ \\
\hline 3 & $\begin{array}{l}\text { Gradient of altitudes } \Delta H / l(l \text { distance } \\
\text { between } H_{\max } \text { and } H_{\min } \text { points within } \\
\text { the knot }\end{array}$ & $<40$ & $>70$ \\
\hline 4 & Combinations of relief types: & \multirow{2}{*}{\multicolumn{2}{|c|}{ "yes" or "no" }} \\
\hline & a) mountain/plain $(\mathrm{M} / \mathrm{P})$ & & \\
\hline & b) mountain/piedmont/plain (M/PM/P) & \multicolumn{2}{|c|}{ "yes" or "no" } \\
\hline & c) mountain/piedmont (M/PM) & \multicolumn{2}{|c|}{ "yes" or "no" } \\
\hline & d) mountain/upland $(\mathrm{M} / \mathrm{U})$ & \multicolumn{2}{|c|}{ "yes" or "no" } \\
\hline & e) mountain/mountain (M/M) & \multicolumn{2}{|c|}{ "yes" or "no" } \\
\hline 5 & $\begin{array}{l}\text { Distance from the intersection } \\
\text { to the nearest lineament of II rank, } \\
R_{2}, \mathrm{~km}\end{array}$ & $<50$ & $>120$ \\
\hline 6 & $\begin{array}{l}\text { Distance from intersection to the } \\
\text { nearest intersection, } R_{\mathrm{int}}, \mathrm{km}\end{array}$ & $<50$ & $>62$ \\
\hline
\end{tabular}

$15,36,42,54,67,71,76$ and 86 . These were regarded as class under examination. The other remaining 65 knots were put into learning set $\left(N_{0}\right)$ for $N$-class.

\subsection{Parameters of the objects}

For the purpose of classification the objects are described by parameters from morphology and MSZ-scheme. They are listed in table 3. These parameters represent indirectly the contrast and intensity of neotectonic movements as well as tectonic parcelling in the vicinities of the knots. Numerical values of the parameters were measured from topomaps and MSZ-scheme within a $50 \mathrm{~km}$ radius around the knot in accordance with the criteria given in Gvishiani et al 1988.

Informativity of each parameter was evaluated on the basis of their one-dimensional distributions (Gvishiani et al 1988). The following parameters were found most informative to divide $D_{0}$ - and $N_{0^{-}}$objects: $H_{\min }, \Delta H, \Delta H / l$, combinations of landforms, $R_{2}$ and $R_{\text {int }}$ (see table 3 ).

\subsection{Discretization and coding}

The parameters of the objects were discretized and the objects were coded by two bits. The thresholds of coding are also given in table 3. As a result all objects of recognition were represented by 12 -components binary vectors.

\subsection{Learning stage}

On the basis of learning set two sets of features which are characteristic for $D_{0^{-}}$and $N_{0}$ - classes respectively were selected by "CORA-3" algorithm. These are given in 
Table 4. Characteristic $D$-features and $N$-features for $M \geqslant 6.5$.

\begin{tabular}{|c|c|c|c|c|c|c|}
\hline \multirow[b]{2}{*}{$\#$} & \multicolumn{6}{|c|}{ Parameters } \\
\hline & $\begin{array}{l}\text { Combination of } \\
\text { relief types }\end{array}$ & $\begin{array}{l}R_{\text {int }} \\
\mathrm{km}\end{array}$ & $\begin{array}{c}R_{2} \\
\mathrm{~km}\end{array}$ & $\begin{array}{c}\Delta H \\
m\end{array}$ & $\Delta H / l$ & $\underset{m}{H_{\min }}$ \\
\hline \multicolumn{7}{|c|}{$D$-features } \\
\hline 1 & & & & & $<70$ & $300-2100$ \\
\hline 2 & & & $<50$ & & & $300-2100$ \\
\hline 3 & & & $<120$ & & $>70$ & $<2100$ \\
\hline 4 & & & $>120$ & & $<70$ & $<2100$ \\
\hline 5 & "yes":M/P, M/PM/P, M/PM & & & & $>40$ & \\
\hline 6 & & & $<50$ & & $>40$ & $<2100$ \\
\hline 7 & & & $<50$ & & $>70$ & \\
\hline 8 & & $<62$ & $<50$ & & & $>300$ \\
\hline 9 & & $<62$ & $<50$ & & $>40$ & \\
\hline 10 & & $<62$ & $<120$ & $>4400$ & & \\
\hline 11 & & $>50$ & $>50$ & $>4400$ & & \\
\hline 12 & & $50-62$ & & $>4400$ & & \\
\hline \multicolumn{7}{|c|}{$N$-features } \\
\hline 1 & & & & & $<70$ & $>2100$ \\
\hline 2 & & & $>50$ & & & $>2100$ \\
\hline 3 & & & & $<2900$ & $<40$ & \\
\hline 4 & & & $<120$ & & $<40$ & \\
\hline 5 & & $>50$ & & & $<40$ & \\
\hline 6 & & $>50$ & & $<2900$ & $<70$ & \\
\hline 7 & "no":M/P, M/PM/P & & $>120$ & & $>40$ & \\
\hline 8 & "yes":M/M or $M / U$ & & $>50$ & $<4400$ & & \\
\hline 9 & "yes":M/M or $M / U$ & & $>120$ & & & \\
\hline
\end{tabular}

table 4. The following thresholds for selection and rejection were used for the selection of characteristic features:

$$
K_{D}=5, \tilde{K}_{D}=6, K_{N}=16, \tilde{K}_{N}=1
$$

\subsection{The recognition stage}

The objects from learning and examination sets were classified according to the following rule. An object was assigned to $D$-class if voting $\left(N_{D}-N_{N}\right)$ was greater or equal to 0 , otherwise assigned to class $N$. As a result all 21 objects originally from $D_{0}$ were classified as potential. Three objects $(10,71,86)$ from the class under examination and 24 objects from $N_{0}$ were also recognized as potential. In total, 48 objects among 97 defined in the Himalaya were recognized as potential for the occurrence of earthquakes of $M \geqslant 6.5$. Their locations are shown in figure 3 .

\subsection{Evaluation of the classification reliability}

With a view to determine the reliability and stability of our results the following two control experiments are carried out:

1. "Seismic Future" ( $S F)$ experiment: This experiment is an attempt to repeat the established classification $W=D \mu N$, using the resultant sets $D$ and $N$ as the new learning sets instead of $D_{0}$ and $N_{0}$. It is generally considered that this experiment is 
successful if less than $5 \%$ of the total number of objects are classified in the experiment differently when compared with their source classification. In the present study anly 4 objects (from 97) changed their classification (less then $5 \%$ ). The following thresholds of selection and contradiction of "CORA-3" algorithm are used:

$$
K_{D}=6, \tilde{K}_{D}=1, K_{N}=10, \tilde{K}_{N}=1 \text {. }
$$

The "physical" idea of SF experiment is rather obvious and natural. We assume that sets $D$ and $N$ are well established. Therefore, strong earthquakes are likely to occur around the objects $\omega^{i} \in D$ in future. Thus we shall have a new learning set $D_{\sigma}^{\prime}=D$. However, if our classification is valid then change in the learning material should not change the result of classification. We consider consistent results of SF experiment as a necessary condition for the confirmation of classification.

2. "Sliding Control" (SC) experiment: It is designed for establishing classifications on the basis of the learning sets $\left(D_{0} / w^{i}\right)$ and $\left(N_{0} / w^{n_{1}+i}\right), i=1,2, \ldots, \max \left(n_{1}, n_{2}\right)$ to check whether classification of the objects belonging to the learning set is stable or not, while they are excluded from the learning set.

The first variant discards the objects $w^{1} \in D_{0}$ and $w^{n_{1}+1} \in N_{0}$, the second variant resets them but discards the objects $w^{2} \in D_{0}$ and $w^{n_{1}+2} \in N_{0}$, etc. If one of the sets $D_{0}$ or $N_{0}$ (with a smaller number of objects) already completely discarded once, we proceed only with the remaining set. We usually consider SC experiment as successful if not above $10 \%$ of objects in each of $D_{0}$ and $N_{0}$ sets change their classification. In our case the percentage was less than 5 .

\section{Identification of earthquake-prone areas for $M \geqslant \mathbf{7 \cdot 0}$}

The available catalogues of earthquakes of the Himalayan arc region do not contain adequate number of earthquakes of $M \geqslant 7.0$ (see table 2) to enable formulation of suitable learning set. We therefore use the procedure of transferring of criteria of earthquake prone areas between Andes of Southern America and Himalayas. Detailed description of the procedure is given by Gvishiani et al (1988).

Criteria transfer is the use of seismicity criteria, established in recognizing potential knots for the occurrence of earthquakes with $M \geqslant M_{0}$ in one region, for identifying the similar knots in the other region.

The necessary prerequisite for using criteria transfer is the uniformity of recognition objects in the regions under consideration. Voting procedure is done under criteria transfer for the objects of one region using the seismicity criteria of another region. For this reason in the criteria, which are transferred, discretization thresholds of parameters are replaced with discretization thresholds defined for those same parameters in that region onto which transfer is made.

The criteria of earthquake-prone areas with $M \geqslant 7.0$ of South American Andes (Filimonov et al 1989) were obtained from the following set of topographic and geomorphic parameters:

$H_{\min }$ - minimum topographic altitude within the knot.

$\Delta H$ - difference of maximum and minimum altitudes.

$R_{1}$ - the distance to the nearest first rank lineament.

$R_{2}$ - the distance to the nearest second rank lineament.

$H_{r}$ - highest rank of the lineament within the knot. 
Table 5. Characteristic $D$-features and $N$-features for $M \geqslant 7 \cdot 0$ (after Filimonov et al. 1989).

\begin{tabular}{|c|c|c|c|c|c|c|}
\hline \multirow[b]{2}{*}{$\#$} & \multicolumn{6}{|c|}{ Parameters } \\
\hline & $\begin{array}{c}\text { Highest rank } \\
\text { of lineament }\end{array}$ & $\begin{array}{c}H_{\max } \\
m\end{array}$ & $H_{\min }$ & $\begin{array}{l}R_{2} \\
\mathrm{~km}\end{array}$ & $\begin{array}{l}R_{1} \\
\mathrm{~km}\end{array}$ & $\begin{array}{c}\Delta H \\
m\end{array}$ \\
\hline \multicolumn{7}{|c|}{$D$-features } \\
\hline 1 & & & & $<64$ & & $>3300$ \\
\hline 2 & & & $<600$ & & & $>3300$ \\
\hline 3 & & & & $<67$ & $<67$ & \\
\hline 4 & $\begin{array}{l}\text { I or II rank } \\
\text { lineament }\end{array}$ & & & & & $>3300$ \\
\hline \multicolumn{7}{|c|}{$N$-features } \\
\hline 1 & & & & & & $<3300$ \\
\hline 2 & not I rank lin. & & & $>67$ & & $<3900$ \\
\hline 3 & & $<3600$ & & & $>64$ & \\
\hline 4 & & & & $>64$ & & \\
\hline 5 & & & $>600$ & $>67$ & & \\
\hline 6 & I rank lineament & & $>600$ & $>64$ & & \\
\hline
\end{tabular}

Table 5 gives the features of $D$ - and $N$-classes. An object is considered to belong to class $D$ if the voting $\left(N_{D}-N_{N}\right) \geqslant 1$, otherwise to class $N$. Using this recognition rule the following 36 Himalaya objects were classified as non-potentially for $M \geqslant 7 \cdot 0$ (see figure 4): $4,6,8,9,10,17,18,23,25,28,29,31,35,39,40,49,53,56,57,66,68$, $70,71,74,75,77,78,84,85,86,90,92,93,94,95,96$.

All the objects associated with known epicenters of earthquakes with $M \geqslant 7.0$ (see table 2) were successfully recognized as potential.

\section{Discussion and conclusions}

From the criteria obtained (table 4), potential $(D)$ knots in the Himalaya are characterized by their small distances to second-rank lineaments $\left(R_{2}<50 \mathrm{~km}\right.$ or $\left.R_{2}<120 \mathrm{~km}\right)$ and to the nearest intersection (Rint $<62 \mathrm{~km}$ ). At the same time $D$-knots also show a large difference in altitudes $(\Delta H>4400 \mathrm{~m})$, large values of altitude-gradient and small values of $H_{\min }\left(H_{\min }<2100 \mathrm{~m}\right)$. Besides, combinations of contrasting types of relief such as mountain slope/piedmont plains and mountain slope/piedmont hills/piedmont/plains are predominant features of $D$-knots. Such a set of characteristic features around $D$-knots indicate a high level of tectonic parcelling and intense neotectonic movements in the vicinity of such knots. Criteria of non-potential $(N)$ knots consisting of the same parameters reveal different values pointing to a lesser degree of tectonic activity around non-potential knots.

Along the Himalaya, majority of $D$-knots are located on the first-rank lineament at the southern boundary and along the transverse second-rank lineaments. $D$-knots are mostly concentrated along a few segments at the southern boundary lineament. The knots including $6,8,9,17,18,19$ and 21 occupy western segment of the lineament where its strike is sharply reoriented in north-west direction and shifting of Himalayan range to north takes place. The other group of knots namely $56,68,70$ and 78 is 


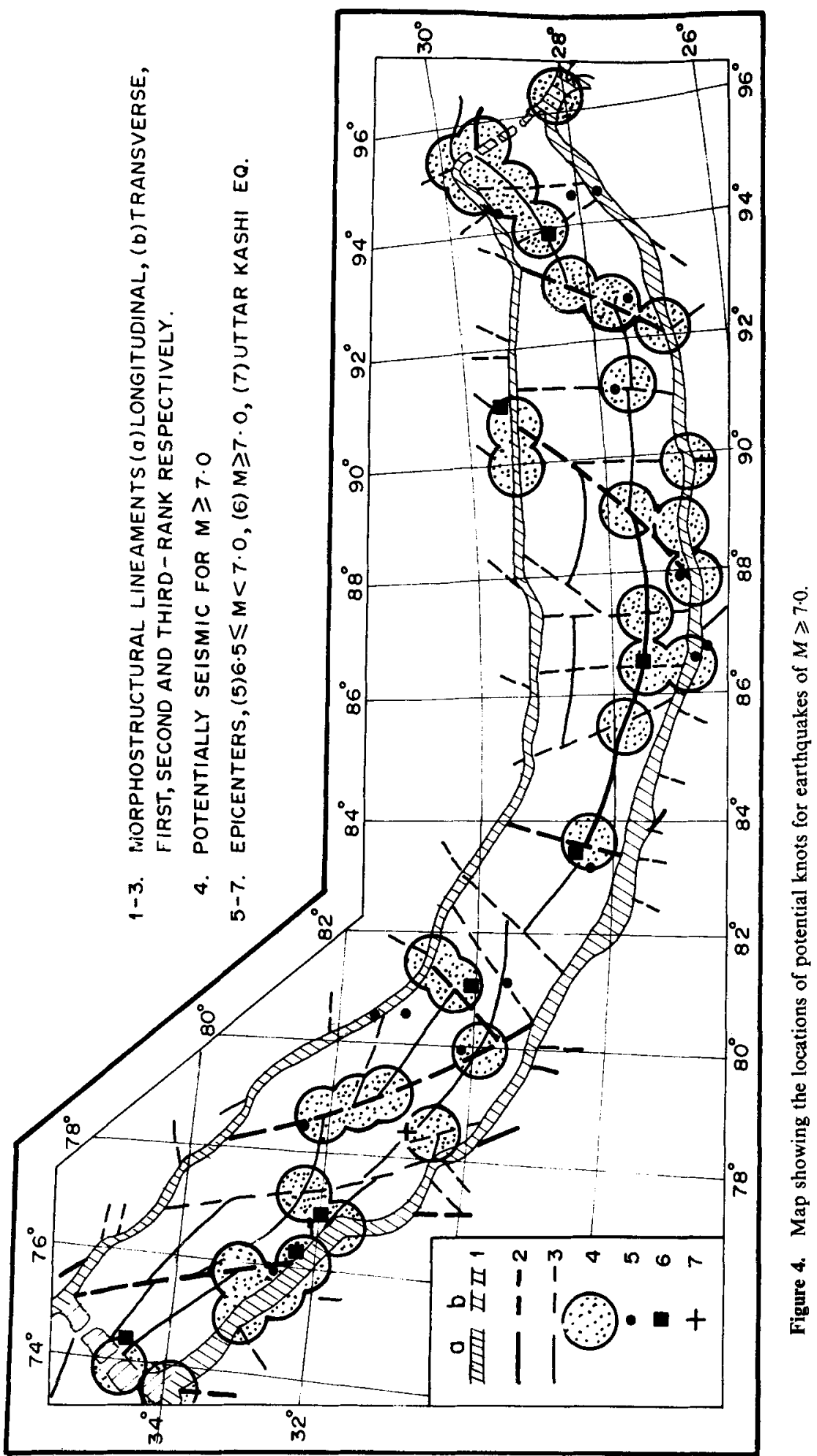


located in the central part of the lineament where piedmont hills disappear, and the junction between mountain slope and accumulative plains is very sharp because of neotectonic movements. The third group of knots namely $86,88,89$ and 96 is located on the eastern part of lineament, where its strike changes from east-west to north-east and shifting of the Himalayan belt to north. Only seven knots $(32,40,74,75,91,92$, 93) on the northern boundary of Himalayas were recognised to be potential. The northern boundary seems to be less earthquake prone as compared with the southern boundary.

The results of pattern recognition reveal that almost $50 \%$ of knots in the Himalayan belt are found to be potential for earthquakes of magnitude $M \geqslant 6.5$. Taking into account the high level of seismicity of the region and positive results of the control experiments, the obtained classification might be considered reliable. The results of this classification were presented earlier, in the symposium on 'Earthquake Prediction held at Strasbourg, France in March 1991 (Gorshkov et al 1991). It is interesting to note the occurrence of earthquake of $M=6.6$ on 19 th October 1991 in the western part of the Himalaya near Uttarkashi. Epicenter of Uttarkashi earthquake is located within the knot 24 which has been recognized as potential for $M \geqslant 6.5$ (see figure 3). The study for $M \geqslant 7.0$ reduces the number of potential knots from 48 to 36 (figure 4). The knot no. 24 associated with Uttarkashi earthquake is recognised as potential in this study as well. It is also significant to note that strong earthquakes in this area were not known earlier.

The areas indicated in figures 3 and 4 provide a possible model of the potential zones for the occurrence of strong earthquake in the Himalayan arc region and could be of much help in defining seismic hazard in the region.

\section{Acknowledgements}

This study has been carried out under the aegies of Indo-Russian ILTP Program (formerly Indo-Soviet) Project B 2:1·2. The authors are grateful to the Department of Science and Technology (DST), New Delhi and Russian Academy of Sciences (Moscow) for providing exchange visits to scientists. They thank Professor V K Gaur (CSIR), New Delhi and Professor V I Keilis-Borok, Director of IIEP, Moscow, the coordinators of the collaborative project for their encouragement and valuable guidance. They also thank Professor D Guptasarma, Director of NGRI, for his stimulating discussions, kind cooperation through out the progress of the work and for according permission to publish this paper.

\section{References}

Dasgupta S, Mukhopadhyay M and Nandy D R 1987 Active transverse features in the central portion of the Himalaya; Tectonophysics 136 255-264

Filimonov M, Zhidkov M and Tumarkin A 1989 Recognition of Earthquake-Prone Areas. XVIII. Southern America Andes $(M \geqslant 7 \cdot 0$ ); Computational Seismology 23 111-125 (in Russian)

Ganser A 1964 The Geology of the Himalayas (New York: Interscience) pp. 289

Ganser A 1974 The Himalayas; In: Mesozoic-Cenozoic orogenic belts (Edinburgh: Scottish Academic Press) pp. 326-339

Ganser A 1983 Geology of the Bhutan Himalaya (Basel-Boston-Stuttgart: Birkhauser Verlag) pp. 176 
Gelfand I, Guberman Sh, Izvekova M, Keilis-Borok V and Rantsman E 1972 Criteria of high seismicity, determined by pattern recognition; Tectonophysics 13 415-422

Gorshkov A, Filimonov M, Chetty T R X and Rao M N 1991 Identification of earthquake-prone areas in the Himalaya belt; EUG VI. Abstracts. Terra, March Strasbourg p. 164

Gvishiani A, Soloviev A 1981 About proximity of strong earthquake epicenters to intersections of morphostructural lineaments in the South America territory; Computational Seismology 13 45-50 (in Russian)

Gvishiani A, Gorshkov A, Rantsman E et al 1988 Identification of earthquake prone areas in regions of moderate seismicity (Moscow: Nauka) pp. 175 (in Russian)

Khain V 1984 Regional geotectonics. Alpine Belt (Moscow: Nedra) pp. 344 (in Russian)

Mukhopadhyay M 1984 Seismotectonics of transverse lineaments in the Eastern Himalaya and its foredeep; Tectonophysics 109 227-240

Olta Y, Akiba C (eds) 1973 Geology of the Nepal Himalayas (Sapporo: Saikom Publishing Co. Ltd.) pp. 290

Rantsman E 1979 Places of earthquakes and morphostructure of mountain countries (Moscow: Nauka) pp. 170 (in Russian)

Varunoday, Gaur V K and Wason H R 1979 Spatial prediction of earthquakes in Kumaon Himalaya by pattern recognition; Mausam 30 253-264

Valdia K S 1976 Himalayan transverse faults and folds and their parallelism with subsurface structures of North Indian plains; Tectonophysics 32 353-386

Valdia K S 1984 Tectonics of folded areas around Indian platform; Proceedings of the 27 International Geological Congress (Moscow: Nauka) Vel. 5, 89-11 (in Russian)

Windley B F 1988 Tectonic framework of the Himalaya, Karakorum and Tibet, and problems of their evolution; Philos. Trans. R. Soc. London A326 3-16 